\title{
“Por Que De Galo, Então, Chamamos Quem Se Castra [...]?” INTERSECCIONALIDADE EM REPRESENTAÇÕES DE SACERDOTES CASTRAdos No IMPÉrio RoMANo
}

\author{
Semíramis Corsi Silva ${ }^{1}$
}

RESUMO

O objetivo deste artigo é analisar representações textuais de sacerdotes considerados praticantes de rituais que envolviam cortes de seus órgãos genitais. Tais intervenções, tratadas aqui como castrações, foram vistas como perda da virilidade e transgenerização para o feminino na literatura grecoromana do período imperial. Sacerdotes castrados podem ser percebidos no mito de Átis (o consorte da deusa frígia Cibele, a Magna Mater), na literatura sobre os sacerdotes dessa deusa (os galli) e nas representações textuais dos sacerdotes da deusa síria Atargátis e do imperador Heliogábalo (218-222). Como não há relatos dessas práticas deixados por seus praticantes, grande parte da documentação que temos sobre os sacerdotes castrados se refere às representações feitas por seus críticos. Diante disso, as fontes utilizadas para o estudo que se apresenta são compostas de textos literários greco-romanos. Neste artigo, tais textos serão analisados à luz de uma perspectiva interseccional, pensando a descrição dos sacerdotes a partir da construção do outro não greco-romano e das normativas de gênero para o uir, o cidadão das camadas abastadas do Império Romano.

PALAVRAS-CHAVE

Sacerdotes castrados; galli; Heliogábalo; representações; interseccionalidade.

\footnotetext{
${ }^{1}$ Professora do Departamento de História e do Programa de Pós-graduação em História da Universidade Federal de Santa Maria - UFSM. Doutora em História pela Universidade Estadual Paulista, UNESP/Franca. Coordenadora do Grupo de Estudos sobre o Mundo Antigo Mediterrânico da UFSM - GEMAM/UFSM. E-mail: semiramiscorsi@yahoo.com.br.
} 


\section{Introdução}

Os sacerdotes castrados e emasculados aparecem na literatura, especialmente, ligados à mitologia da deusa Cibele, a Magna Mater (Grande Mãe) dos romanos, cuja história envolve o corte dos membros viris de seu consorte Átis, o que teria originado um tipo de sacerdote tido como emasculado, que realizava o culto da Grande Mãe, o gallus. Semelhante às representações do rito que envolve a perda de virilidade dos sacerdotes de Cibele, os galli, temos também as histórias sobre os sacerdotes da deusa síria Atargátis, contadas por Apuleio e Luciano de Samósata. Da mesma maneira, em outros trabalhos de minha autoria, tenho interpretado as representações textuais do imperador romano Marco Aurélio Antonino, mais conhecido pela tradição como Heliogábalo (218-222) devido ao seu sacerdócio ao deus Elagabal, como estando ligado aos ritos dessa divindade, também de origens siríacas. ${ }^{2}$ Tal rito a Elagabal, em minha leitura, tinha como componente práticas de intervenção no corpo do sacerdote, o que fez com que a imagem de Heliogábalo nos textos do Império Romano fosse transmitida carregada de hipérboles e demais exageros retóricos, trazendo seu desejo em cortar seu pênis e fazer uma vagina em seu corpo na visão de seu principal crítico, o escritor Dião Cássio, contemporâneo de Heliogábalo.

Portanto, há uma série de textos escritos em latim e em grego, do período romano, que apresentam estes sacerdotes considerados emasculados em seu corpo, suas vestimentas e suas performatividades, muitas vezes em tom de zombaria e, em geral, de forma bastante negativa. ${ }^{3}$ No entanto, não há informações em si das práticas de tais

\footnotetext{
${ }^{2}$ Refiro-me aos textos: Identidade cultural e gênero no Principado Romano: uma proposta de análise interseccional das representações do imperador Heliogábalo (século III E.C.), Phoînix, vol. 24, 2018, pp. 142-166; Heliogábalo vestido divinamente: a indumentária religiosa do imperador sacerdote de Elagabal, Arys. Antigüedad: Religiones y Sociedades, vol. 1, 2019, pp. 251-276 e "Não me chame de senhor, pois eu sou uma senhora": a performatividade transgênero do imperador Heliogábalo (218-222). O último texto está no prelo e será publicado na obra O Império Romano no século III. Crises, Transformações e Mutações, sob minha organização e de Moisés Antiqueira. Previsão de publicação para 2021 pela Editora Desalinho.

3 Sobre o conceito de performatividade de gênero, utilizo os estudos de Judith Butler (2010). Butler descreve o sujeito como sujeito-em-processo, que é construído no discurso pelos atos que executa. Portanto, o sujeito é uma construção performativa, havendo formas de construir a identidade que irão perturbar interessados em preservar as oposições existentes como macho/fêmea, masculino/femininino, gay/hétero e assim por diante. Dessa maneira, a identidade de gênero para Butler é uma sequência de atos, uma performatividade (algo que se faz, mas não algo que se é), uma prática discursiva aberta a ressignificações. E, embora não seja possível trabalhar com a ideia de subjetividade ao analisar personagens do mundo antigo pelas lentes de seus opositores, cabe pontuar que há como analisar os discursos que carregam olhares sobre a performatividade dos sacerdotes, mostrando como ela perturba os interesses em manter uma ordem constitutiva sobre o que é homem e o que é mulher em seus respectivos modelos.
} 
sujeitos por meio de seus próprios relatos. Assim, a principal documentação que temos sobre eles são representações feitas por seus críticos. ${ }^{4}$

Sabendo disso, o objetivo deste artigo é analisar as representações religiosas dos sacerdotes conhecidos na literatura greco-romana como castrados e emasculados a partir de uma perspectiva interseccional. Portanto, viso pensar a construção de modelos normativos de gênero e identidade cultural sobrepostos nos suportes literários em meio às representações de rituais e personagens religiosos. Também voltarei minha atenção para elementos sociais e de poder presentes nestas representações.

É importante mencionar que o termo castrado está sendo usado aqui para definir práticas que envolviam cortes das genitais dos sacerdotes estudados, uma vez que é um termo amplamente usado nas traduções modernas dos textos antigos e que, em minha leitura, facilita a compreensão contemporânea do ato visto como um processo de emasculação. ${ }^{5}$ No entanto, este termo não é comumente usado nos textos analisados. ${ }^{6}$ Os textos mencionam cortes, feridas e mutilações nas/das partes íntimas destes homens, usando diversos termos em grego ou latim para trazer essa ideia. ${ }^{7}$ Luciano, por exemplo, usa o verbo $\tau \dot{\varepsilon} \mu v \omega$, em grego, remetendo ao ato de cortar, fazer incisões (A deusa síria, 20). Marcial, em latim, utiliza o termo praecide, do verbo praecido, também no sentido de cortar (Epigramas, 9, 2, 13). ${ }^{8}$ Já o termo emasculado está sendo usado para traduzir

\footnotetext{
${ }^{4}$ Entendo representações seguindo Roger Chartier (1988, p. 19), que pensa representações como a realidade na ótica de quem representa e não como meras abstrações. Para Chartier (1988, p. 17), as representações variam segundo as disposições dos grupos e aspiram à universalidade. Porém, são sempre determinadas pelos interesses de dominação do proponente, são estratégias para impor autoridade e poder. Assim sendo, as representações dos sacerdotes analisados, mesmo sendo hiperbólicas, são o real para seus detratores, é como eles enxergam o outro que se passa como transgredindo as fronteiras de gênero e identidade cultural. Com elas, para mim, os escritores objetivam impor sua visão de como eram os sacerdotes castrados, em estratégias de controle e dominação.

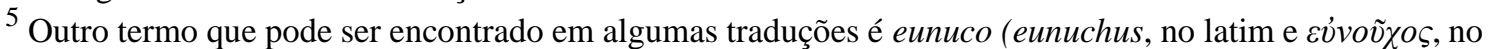
grego). Optei por não utilizar o termo eunuco, ainda que Piotor Scholz (2001, p. IX) defenda que os "eunucos não eram simplesmente os 'vigilantes da cama', como o termo grego sugere. Nem apenas escravos, bem como não apenas atores. Eles podiam ser ascetas, sacerdotes, magos, estudiosos, físicos, comandantes militares, administradores ou oficiais sêniores das cortes no Ocidente ou no Oriente". Minha opção por utilizar o termo castrado vem da ideia de corte das genitálias que a palavra sugere. No entanto, é preciso frisar que o termo castração pode ser compreendido como uma generalização de ritos e personagens diferentes e deve ser utilizado com cuidado para que não seja confundido com os famosos processos da Época Medieval e Moderna realizados em cantores (os castrati), visando preservar a voz aguda.

${ }^{6}$ Dos textos usados neste artigo é possível ver que Marcial o utiliza em Epig., 3, 81.

${ }^{7}$ Sobre os termos em grego e latim que se referiam a tipos de cortes, ver Scholz, 2001, p. 112.

${ }^{8}$ Para todos trechos da documentação citados, coloquei o original em grego ou latim em nota para que o leitor possa conferir os termos usados pelos escritores antigos. Como não se trata de um trabalho de tradução, julguei desnecessário trabalhar todos os termos que falam sobre o corte nas genitálias no comentário acima. Mas, ressalto que é importante perceber que todos autores antigos usados aqui trazem a
} 
uma série de palavras gregas e latinas que trazem a ideia de ambiguidade de gênero, feminilidade, passividade, moleza e, consequentemente, perda da virilidade e inversão para o feminino. ${ }^{9}$ Seria uma transgenerização, para utilizar um conceito moderno que, em minha leitura, facilita a compreensão do processo representado nos textos para se referir a esses sacerdotes vistos transitando para outro gênero e até para outro sexo com os processos de castração, segundo a percepção dos escritores.

Com isso definido, começarei minha análise das representações literárias dos sacerdotes considerados, nos termos escolhidos, castrados e emasculados, se transgenerizando.

\section{Representações de sacerdotes castrados no Império Romano}

Tratarei aqui de representações dos galli, dos sacerdotes da deusa síria Atargátis e do imperador Heliogábalo presentes em textos do Principado, focando, em especial, nos processos de castração. ${ }^{10}$ Começarei pelos galli. Para isso, é preciso voltar aos escritos do último século da República a fim de compreender o aparecimento da imagem dos sacerdotes de Cibele nos textos romanos a partir do mito que explicará o rito.

Há muitas versões do mito de Cibele e Átis e da explicação para o rito de castração dos galli nos textos antigos. No contexto romano, a versão mais conhecida, e base para as posteriores, é a do poeta Catulo, que viveu entre 87 e 54 AEC. Segundo Catulo (Poema 63), Átis, em êxtase frenético (stimulatus ibi furenti rabie), corta seus membros viris com um sílex por devoção à Cibele (vagus animis devolvit ili acuto sibi pondera silice). Ainda que Catulo não fale sobre a origem e função do rito, o ato, na visão do poeta, transforma Átis em uma falsa mulher (notha mulier) e em um homem estéril (ego vir sterilis ero).

ideia de corte e/ou retirada de algo. Sobre as versões citadas das fontes, utilizei traduções em português realizadas por especialistas, verificando também traduções para outras línguas modernas. As traduções de trechos de fontes sobre Heliogábalo são minhas.

9 Tratam-se de termos como cinaedus, pathicus, semimas, effeminatus e mollis, no latim e $\mu \alpha \lambda \alpha \kappa o ́ \varsigma$ e

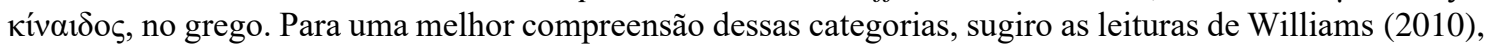
Halperin (2001) e Thuillier (2013).

${ }^{10}$ Os escritores cristãos da Antiguidade Tardia não deixaram de representar negativamente os galli. Fírmico Materno (Sobre o erro das religiões profanas, 4, 2), astrólogo convertido ao cristianismo do período de Constantino (306-337), e Santo Agostinho (A cidade de Deus, 7, 26), bispo de Hipona, por exemplo, observaram a performatividade considerada feminina dos sacerdotes de forma bastante crítica. Conforme Will Roscoe (1996, p. 196), a religiosidade mistérica de Cibele foi uma das principais rivais do cristianismo em sua fase de afirmação pela maneira como os galli transgrediam as fronteiras de gênero. No entanto, como em tais representações estão contidas normativas de corpo e gênero próprias do cristianismo que fogem dos objetivos deste artigo, não as analisarei. 
Sobre os galli, Catulo os trata no feminino, ${ }^{11}$ deixando claro seu tom de reprovação. No final do verso, clama que Cibele mantenha sua fúria longe dele, pois seus seguidores são feitos em estado de agitação e insanidade, o que seria preciso para a realização de um ato tão horrendo:

Deusa grande, ó Cibele, senhora do Díndimo,

longe de minha casa vá a sua fúria,

outros leva agitados, outros leva insanos.

(Catulo, Poema 63, 91-93. Tradução de João Angelo Oliva Neto) ${ }^{12}$

Também da primeira metade do século I AEC, em Da Natureza das coisas (2, 615618), o poeta Lucrécio fornece sua explicação para a razão das castrações dos galli. Segundo Lucrécio, os sacerdotes de Cibele se fazem galli a fim de mostrar que os homens que violam a majestade da Grande Mãe e são ingratos a seus pais não devem ser merecedores de ter filhos. Lucrécio, no entanto, apenas comenta isso, não tecendo considerações sobre a realização do processo de castração.

Do final do século I AEC, o historiador Dionísio de Halicarnasso, em Antiguidades Romanas $(2,19)$, conta que os ritos para a deusa Cibele, sendo estrangeiros e tendo sido introduzidos de acordo com oráculos, eram realizados em Roma de forma adaptada. Seus sacerdotes e sacerdotisas, segundo ele, eram frígios e estavam encarregados de levar a imagem da deusa em procissão pela cidade, quando também saíam pedindo esmolas e tocando tamborins e flautas em homenagem à Mãe dos Deuses. Mas, por decreto do Senado, nenhum cidadão romano podia segui-los em procissão usando a túnica que fazia parte da indumentária sacerdotal. Dionísio não diz nada sobre a visão dos galli como femininos ou sobre possíveis processos de castração. Porém, já apresenta o quanto estes ritos eram, embora aceitos na religiosidade oficial da cidade, estranhos a ponto de o

${ }^{11}$ Como quando os chama de gallae, vocativo plural, no verso 12: "Ei Galas!, ide aos altos bosques de Cibele, ide juntas" (agite ite ad alta, Gallae, Cybeles nemora simul). E no verso 34: "lépido os pés, o guia as Galas seguem rápidas" (rapidae ducem secuntur Gallae properipedem itaque), onde Gallae está no nominativo plural.

12 dea magna, dea Cybelle, dea domina Dindymi,

procul a mea tuus sit furor omnis, era, domo:

alios age incitatos, alios age rabidos (Catulo, Poema 63, 91-93). 
Mare Nostrum, ano 2020, v. 11, n. 1 .

Senado decretar a proibição de que cidadãos romanos se tornassem sacerdotes da Grande Mãe.

A partir desses relatos do período republicano, haverá uma série de representações compostas no Principado sobre o mito de Cibele e a castração dos galli. Sobre a introdução oficial da festa de Cibele no calendário das festas romanas, quem deixou o melhor relato foi Ovídio nos Fastos $(4,247-272) .{ }^{13}$ Ao falar sobre a prática de castração dos sacerdotes da Mãe do Ida, nome pelo qual a deusa também era chamada, Ovídio, escrevendo no final do século I AEC e início do século I EC, diz que: "Por que de galo, então, chamamos quem se castra/ quando da Frígia a Gália tanto dista?" (Cur igitur Gallos qui se excidere, vocamus/cum tanto a Phrygia Gallica distet humus) (Fastos, 4, 361). O termo usado aqui por Ovídio para se referir ao que é traduzido como a autocastração é excido, que tem sentido de deixar cair, tirar fora. Assim sendo, em Ovídio é clara a ideia de que os galli cortavam algo para fora de si de forma voluntária. Nessa passagem, também está a percepção de que estes sacerdotes são sempre estrangeiros, de fora de Roma. O poeta se questiona sobre a razão do nome gallo para definir estes sacerdotes, pois eles são vistos como vindo da Frígia, terra distante da Gália. Sua explicação é que, na Frígia, havia um rio chamado Galo, que enlouquecia quem bebia sua água. ${ }^{14}$

Em outra passagem (Fastos, 4, 222-221), ao relatar o mito de Átis para explicar a castração dos sacerdotes que o seguiam como exemplo, o poeta se pergunta: “'O ímpeto de se castrarem de onde vem"'? ( 'Vnde venit' dixi 'sua membra secandi impetus'). E já no relato sobre a autopunição da castração de Átis por ter traído a deusa, Ovídio escreve:

Com u'a pedra afiada ele mutila o corpo

e arroja na poeira a cabeleira

"Mereci, foi a voz. 'Pago com sangue as penas;

13 A festa de Cibele (Megalensia, renomeada por Augusto como Ludi Matri deum Magnae Idaeae) era celebrada em Roma no início da primavera. Conforme Tito Lívio (Histórias, XXIX, 14, 16-17), a festa para Cibele ocorria na véspera dos idos de abril. Ovídio fala da festa dessa deusa no Livro IV de Fastos, dedicado ao mês de abril. Conforme Roscoe (1996, p. 201), a festa mudou para março no período de governo do imperador Cláudio (41-54). Já Scholz (2001, p. 103), diz que é possível que o festival de Átis tenha sido colocado em março para se separar do festival de Cibele, mantido em abril, e que o ponto alto do festejo de Átis era o dia 24 de março, o Dia do Sangue. Jaime Alvar (2008, p. 282), por sua vez, defende as datas de 15 a 18 de março para a festa de Átis e 4 a 10 de abril para a festa de Cibele.

${ }^{14}$ Sobre a etimologia do nome dado aos sacerdotes de Cibele, ver Alvar (2008, p. 252). 
Semíramis Silva. "Por que de galo, então, chamamos quem se castra [...]?"

morra a parte de mim que me malfez.

Morra', dizia, e tira o peso da virilha

- e da virilidade nada resta.

O exemplo é esse furor: arrancando os cabelos

os adamados servos se emasculam."

(Ovídio, Fastos, 4, 237-244. Tradução de Márcio Meirelles Gouvêa Júnior) ${ }^{15}$

Ovídio ainda retrata a festa como barulhenta e agitada. A deusa é levada nos delicados ombros de seus sacerdotes (ipsa sedens molli comitum cervice feretur). A delicadeza era a antítese da masculinidade e fazia alusão ao tipo mais extremo de homem sem virilidade, os castrados, em diversos poemas (Williams, 2010, p. 140), como abaixo:

Eunucos tocarão tímpanos retumbantes,

Tintilarão os címbalos de bronze;

Será levada a deusa em delicados ombros,

co’ exaltação gritada pelas ruas.

Os jogos chamam, soa a cena: Olhai, quirites!

Cesse nos tribunais a litigância.

(Ovídio, Fastos, 4, 183-188) $^{16}$

15 ille etiam saxo corpus laniavit acuto, longaque in immundo pulvere tracta coma est, voxque fuit 'merui! meritas do sanguine poenas. a! pereant partes, quae nocuere mihi! a! pereant' dicebat adhuc, onus inguinis aufert, nullaque sunt subito signa relicta viri. venit in exemplum furor hic, mollesque ministri caedunt iactatis vilia membra comis.' (Ovídio, Fastos, 4, 237-244).

16 ibunt semimares et inania tympana tundent,

aeraque tinnitus aere repulsa dabunt:

ipsa sedens molli comitum cervice feretur 
Mare Nostrum, ano 2020, v. 11, n. 1 .

O poeta Marcial, de meados do século I e início do século II EC, também se referiu aos galli como femininos em vários epigramas $(2,86.1-6 ; 5,41)$ e fez menções aos processos de castração em muitos outros. Como é possível ler nas passagens a seguir:

Glipto, porque teu pau não subia, o cortaste:

Pra que tais ferros, tonto? Eras eunuco. ${ }^{17}$

(Marcial, Epig., 2, 45. Tradução de Fábio Cairolli) ${ }^{18}$

Que tens co’ o abismo feminil, Bético Galo?

Varões deve lamber a língua ao meio

Por que te foi cortado o pau com telha sâmia,

se de bocetas, Bético gostava?

A cabeça se castre pois, galo do membro

Cibele enganas: és varão co’a boca.

(Marcial, Epig., 3, 81) ${ }^{19}$

urbis per medias exululata vias.

scaena sonat, ludi que vocant, spectate, Quirites,

et fora Marte suo litigiosa vacent (Ovídio, Fastos, 4, 183-188).

${ }^{17} \mathrm{O}$ tradutor brasileiro opta aqui por traduzir o termo gallus como eunuco. Considero mais pertinente, por razões já explicadas em nota, traduzir por galo ou castrado.

${ }^{18}$ Quae tibi non stabat praecisa est mentula, Glypte.

Demens, cum ferro quid tibi? Gallus eras (Marcial, Epig., 2, 45).

${ }^{19}$ Quid cum femineo tibi, Baetice Galle, barathro?

Haec debet medios lambere lingua uiros.

Abscisa est quare Samia tibi mentula testa,

Si tibi tam gratus, Baetice, cunnus erat?

Castrandum caput est: nam sis licet inguine Gallus,

Sacra tamen Cybeles decipis: ore uir es (Marcial, Epig., 3, 81). 
Semíramis Silva. "Por que de galo, então, chamamos quem se castra [...]?"

$[\ldots]$

Vai agora, Cibele, e capa as bichas ${ }^{20}$ pobres:

este é o pinto digno de cutelo.

(Marcial, Epig., 9, 2, 13-14) ${ }^{21}$

Bácara, régio, deu o pau pra ser curado

por médico rival. Galo será.

(Marcial, Epig., 11, 74) 22

Nos quatro epigramas acima, Marcial deixa claro, pelo menos em sua visão, o que era cortado nestes homens: o pênis. Isso pode ser visto no uso do termo mentula, palavra usada em tom de zombaria para se referir ao pênis e que aparece quarenta e quatro vezes nos poemas de Marcial (Ribeiro Junior, 2016, p. 133) e no uso da palavra penis, uma gíria latina para se referir ao órgão sexual masculino, assim como mentula. Além disso, no Epigrama 3, o poeta conta que, mesmo após o processo de castração, o sacerdote bético engana a deusa realizando sexo oral em mulheres (cunnum lingere), o que o faz bastante indigno de qualquer maneira, pois denota passividade (Benedito Ribeiro, 2016, p. 134). Isso mostra a hierarquia de gênero não pelo ato heterossexual ou homossexual, categorias inexistentes na época de Marcial, mas pela submissão vista no ato de fazer sexo oral em alguém.

Na Sátira VI, o poeta Juvenal, contemporâneo de Marcial, também lança seu olhar crítico contra os galli. Nesta longa sátira, Juvenal aconselha homens que irão se casar, mais especificamente seu amigo Póstumo, sobre os perigos das mulheres. Tudo isso,

\footnotetext{
${ }^{20}$ A palavra cinaedos é traduzido aqui, por Fábio Cairolli, como bichas, uma vez que é uma zombaria extremamente negativa no contexto romano.

${ }^{21}$ I nunc et miseros, Cybele, praecide cinaedos:

Haec erat, haec cultris mentula digna tuis (Marcial, Epig., 9, 2, 13-14).

22 Curandum penem commisit Baccara Raetus

Rivali medico. Baccara Gallus erit (Marcial, Epig., 11, 74).
} 
Mare Nostrum, ano 2020, v. 11, n. 1 .

Juvenal faz de forma bastante misógina. Se ele é tão ofensivo com as mulheres, com homens vistos como mulheres o tom será extremamente negativo:

Do marido, ou das perdas, que ele sofre

Não lhe importa saber; com ele habita

Qual se vizinha fora, e mais ainda

Amigos seus, e escravos maltratando,

Sua casa arruinar da furiosa

Belona, ou de Cibele o choro inteiro

Em casa admite, a que preside infame

Sacerdote castrado, venerável

Por infando prestígio: roucas tubas,

Tambores infernais da plebe infame

O seguem: Frígia tiara lhe orna a fronte,

E dando horrendos brados, aconselha

Que evitem do Setembro o advento breve,

E o dos ventos Austrais perniciosos,

Se de ovos cento, oferta expiatória

Não derem, e as cor-de-rosa velhas roupas,

Porque dos males que o prover aventa,

Naqueles trapos todo o nóxio fique, 
Semíramis Silva. "Por que de galo, então, chamamos quem se castra [...]?"

Purificado sendo esse ano inteiro. ${ }^{23}$

(Juvenal, Sátira VI. Tradução de Francisco Antônio Martins Bastos)

Nas linhas acima, Juvenal fala de mulheres adeptas de cultos como o da Grande Mãe. Extremamente supersticiosas, elas se deixam enganar por sacerdotes femininos (semivir) que cortam sua genitália mole (mollia qui rapta secuit genitalia testa). O quadro pintado aqui mostra o culto como estrangeiro, horrendo, barulhento e plebeu. Juvenal apresenta claramente, em minha leitura, como elementos do feminino (as mulheres e os sacerdotes castrados) são vistos interseccionados à sua aversão ao estrangeiro e ao grupo social da plebe.

Sobre os sacerdotes da deusa Atargátis, a Deusa Síria como também era conhecida, Apuleio deixa um interessante testemunho em $O$ asno de ouro (VIII, 24-28), texto escrito no século II EC. Apuleio os descreve como meninas (puellae), semi-homens (semuiris) e efeminados (effeminati). Apuleio fala de suas roupas coloridas e de linho e seda, de seu cortejo barulhento, de seus rostos maquiados, comparando-os às Bacantes. ${ }^{24}$ Sobre o processo de intervenção no corpo dos sacerdotes, Apuleio não comenta claramente o que acontecia, mas diz que o processo era uma carnificina (carnificina) e que: "Podia-se ver o solo, sob o relampejar dos gládios e o entrecruzar de chicotadas, molhado do impuro sangue desses efeminados"25 (O asno de ouro, VIII, 28).

${ }^{23}$ nulla uiri cura interea nec mentio fiet damnorum. uiuit tamquam uicina mariti, hoc solo propior quod amicos coniugis odit et seruos, gravis est rationibus. Ecce furentis Bellonae matrisque deum chorus intrat et ingens semiuir, obscaeno facies reuerenda minori, mollia qui rapta secuit genitalia testa iam pridem, cui rauca cohors, cui tympana cedunt, plebeia et Phrygia uestitur bucca tiara. grande sonat metuique iubet Septembris et Austri aduentum, nisi se centum lustraverit ouis et xerampelinas ueteres donauerit ipsi, ut quidquid subiti et magni discriminis instat in tunicas eat et totum semel expiet annum (Juvenal, Sátira VI, versos 508 ao 521).

${ }^{24}$ Roscoe (1996, p. 202) percebe que parte das críticas literárias aos sacerdotes castrados estava relacionada a comparações sobre eles feitas, pelos escritores antigos, com os Coribantes e Curetes, praticantes de ritos projetados em benefícios individuais (ao invés de honrar um deus pelo coletivo), em cultos que visavam uma catarse por parte dos espectadores.

25 Cerneres prosectu gladiorum ictuque flagrorum solum spurcitia sanguinis effeminati madescere (Apuleio, $O$ asno de ouro, VIII, 28). 
Will Roscoe (1996, p. 202) diz que: "Embora exagerado pelo efeito cômico, o relato de Apuleio é confirmado em seus detalhes básicos por muitas outras fontes". Trata-se dos relatos de Luciano em Lúcio ou o asno e de Brabio na fábula $O$ asno e os sacerdotes de Cibele (Fábulas, 141). ${ }^{26}$ Ambos os autores narram uma história semelhante à história de Apuleio em torno de um asno, provavelmente, fruto de um substrato comum que pode ter sido o texto de Apuleio ou pode, da mesma forma, ter influenciado Apuleio. Luciano, escrevendo sob o governo de Marco Aurélio (161-180), traz um relato bem parecido com o de Apuleio em relação ao destino do asno da história: ter sido comprado para servir aos sacerdotes da Deusa Síria. Sobre tais sacerdotes, o texto de Luciano (Lúcio ou o asno, 37) também os coloca como femininos de forma bastante crítica, mas vai além do que relatara Apuleio ao mencionar os órgãos cortados no rito, contando que estes sacerdotes faziam cortes em seus antebraços ( $\tau o \grave{v} \varsigma \pi \dot{\eta} \chi \varepsilon \varepsilon \varsigma$ ) e cortavam sua línguaa ( $\tau \dot{\eta} v$ $\gamma \lambda \tilde{\omega} \tau \tau \alpha \nu$ ), descrevendo um ritual feminino sangrento ( $\mu \alpha \lambda \alpha \kappa o \tilde{v} \alpha i ̈ \mu \alpha \tau o \varsigma)$.

Já Brabio, autor de fábulas gregas cuja trajetória é bem desconhecida, mas que, possivelmente, era sírio e viveu no século III EC, conta, em uma fábula curta, que um asno foi comprado pelos sacerdotes mendicantes e sem escrúpulo de Cibele. Brabio não fala nada sobre os sacerdotes serem femininos, apenas que eles contavam de aldeia em aldeia sobre a mutilação do feminino Átis.

Em A deusa síria, Luciano traz novos elementos para se pensar as representações dos sacerdotes castrados. No texto, um relato de viagem, o autor busca compreender a origem de um templo dedicado a uma divindade feminina que ele chama de Hera, mas que os estudos apontam ser a síria Atargátis, na cidade síria de Hierápolis. Ao longo das histórias em torno do templo, Luciano relata os mitos sobre as origens do culto dos sacerdotes da deusa, misturando-os com relatos sobre Átis e Reia. ${ }^{27}$ Assim, Luciano conta que a deusa Reia cortou o deus Átis e, desde então, ele abandonou a vida de homem e passou a se vestir como mulher, celebrando orgias. Foi Átis quem chegou até a Síria e fundou o templo em Hierápolis para a deusa que se assemelha à Reia grega. Os sacerdotes,

\footnotetext{
${ }^{26}$ Há discussões sobre a autoria dessa obra ser mesmo de Luciano. Por isso, muitas vezes, a obra é atribuída como de Pseudo-Luciano. Há também discussões sobre suas grandes semelhanças com $O$ asno de ouro, de Apuleio. Para iniciar esse debate, sugiro a leitura da introdução ao texto de Lúcio ou o asno, da Editora Gredos e a introdução ao texto da edição publicada pela Harvard University Press.

27 Reia é uma Grande-Mãe cretense arcaica. Em Hesíodo, ela se transforma em uma titânida que, unindose ao irmão Cronos, gera Héstia, Deméter, Hera, Hades, Posídon e Zeus. "Na época romana (30 a.C. - 527 d.C.) e, portanto, bem tardiamente, Reia, antiga divindade da vegetação, acabou fundindo-se com a divindade oriental Cibele, a "mãe dos deuses"” (Brandão, 2014, p. 555), o que é possível ver neste relato de Luciano.
} 
que Luciano chama de galli, se cortam em honra à deusa como Átis. Outra versão das origens do templo, mais credível, segundo Luciano, seria a de que ele foi fundado por Dioniso, havendo ali uma inscrição que conta isso. Luciano diz que há também no templo uma estátua com uma figura itifálica, assim como estátuas de falos gigantes colocados pelo deus.

Os Gregos erigem, em honra de Dioniso, uns falos, sobre os quais colocam uns bonecos minúsculos feitos de madeira, com enormes partes pudendas. Chamam a estes [bonecos] "nervos tesos". Também existe um tal objeto dentro do templo. Do lado direito do templo há um boneco minúsculo, de bronze, que tem um membro viril enorme. (Luciano, A deusa síria, 16. Tradução de Custódio Magueijo) ${ }^{28}$

Luciano não realiza nenhuma menção sobre a relação desses falos e de Dioniso com a castração dos sacerdotes do templo. No entanto, em uma passagem mais adiante, Luciano fornece pistas sobre a ligação destes falos como potência simbólica capaz de trazer prosperidade:

Duas vezes por ano, um homem sobe a um destes falos e permanece no alto do falo por um período de sete dias. O motivo desta subida, diz-se que é o seguinte: Na sua maioria, crêem que [o homem], lá tão alto, está em contacto com os deuses e pede prosperidade para toda a Síria, e os deuses atendem às preces mais de perto. (Luciano, A deusa síria, 28) ${ }^{29}$

É possível conjecturar que as castrações tinham o mesmo intuito de fornecer potencialidade à ação dos sacerdotes. Sobre as castrações rituais, Luciano ainda narra mais duas versões de suas origens. Uma delas seria a de que um homem chamado Combabo, funcionário real, cortou seus órgãos genitais para não sucumbir ao desejo pela rainha Estratonice, esposa de Seleuco e fundadora do templo de Hierápolis.

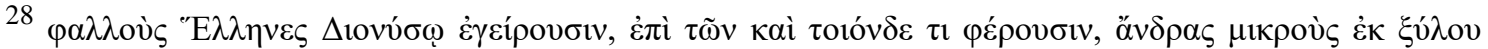

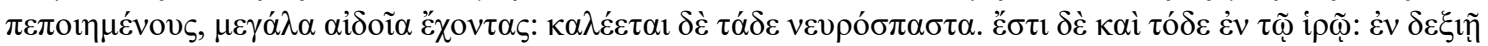

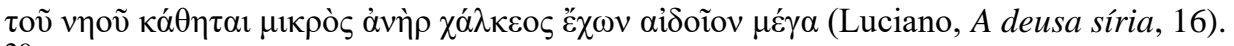

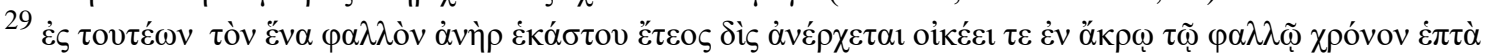

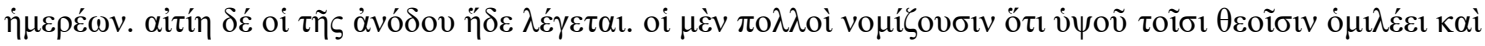

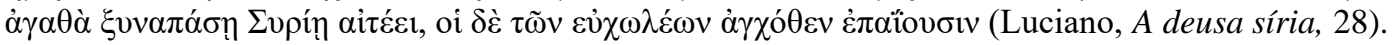


Mare Nostrum, ano 2020, v. 11, n. 1 .

Ditas estas palavras, fez-se [um homem] incompleto, e tendo cortado as partes pudendas, meteu-as num pequeno vaso com mirra, mel e outros perfumes, tudo misturado. E depois de marcar [o vaso] com o selo que usava, tratou de curar a ferida. (Luciano, A deusa síria, 20) $)^{30}$

É a partir dessa história que algumas pessoas explicavam a origem do rito da castração, conforme Luciano, pois os amigos de Combabo passaram a se castrar em consolação a ele (A deusa síria, 26). Em outra versão contida na mesma passagem, Luciano conta que Hera passou a inspirar outros homens a seguirem Combabo para que ele não fosse o único a chorar pela sua virilidade ( $\tau \tilde{\eta} \dot{\alpha} v \delta \rho \eta \dot{\eta} \eta)$. Portanto, Luciano cita que Combabo é tido como feminino, dizendo que há, ainda nos dias de sua visita, uma estátua dele no templo: "Então o rei, em homenagem à sua virtude e aos seus bons ofícios, decidiu erigir-lhe uma estátua de bronze dentro do templo. E ainda hoje existe no templo, em sua honra, um Combabo de bronze, obra de Hérmocles de Rodes, com formas de mulher, e vestes de homem" (A deusa síria, 26). ${ }^{31}$

Sobre as roupas femininas, elas passam a ser usadas por Combabo para que as mulheres não sejam capazes de se apaixonar por ele (A deusa síria, 27), sendo este o motivo pelo qual os sacerdotes do templo também usam vestes de mulher. Da mesma forma, então, os sacerdotes de Atargátis se castram e se emasculam a partir da atitude de Combabo, na visão de Luciano:

Uma vez instituído este costume, ele permanece até hoje. Todos os anos, muitos homens se castram dentro do templo e se feminizam, quer para consolarem Combabo, quer para agradarem a Hera, e por isso se castram. Deixam de usar vestes

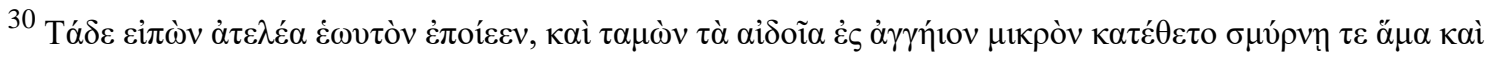

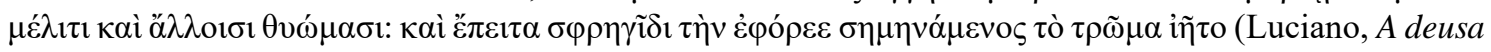
síria, 20).

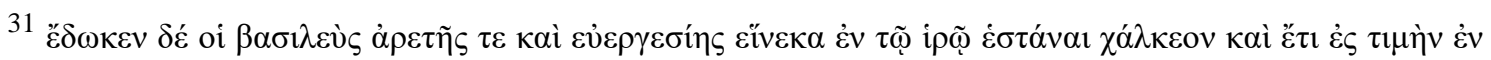

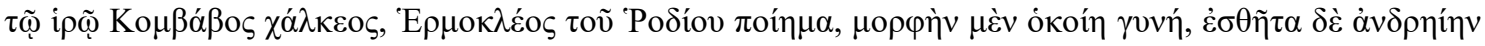

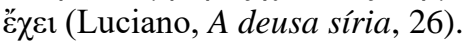


Semíramis Silva. "Por que de galo, então, chamamos quem se castra [...]?"

masculinas, passam a envergar vestidos femininos e a executar trabalhos de mulher. (Luciano, A deusa síria, 27) $)^{32}$

Como visto, Luciano não deixa explícito o que Combabo corta em seu corpo. No entanto, ele comenta que isso o torna impotente sexualmente ${ }^{33}$ (Deusa síria, 20). Ele também deixa pistas para compreendermos que havia uma ligação dos cultos realizados no templo de Hierápolis com o falo tido como sagrado quando comenta sobre o rito de subida no falo.

Ainda se tratando de cortes no corpo dos sacerdotes, Luciano conta que: "Em dias determinados, a multidão reúne-se no templo, e muitos Galos e homens consagrados, a que atrás me referi, celebram as cerimónias, retalham os braços e ferem as costas uns dos outros" (Luciano, A deusa síria, 50). ${ }^{34}$

É importante destacar que a festividade principal do templo ocorria no início da primavera, conta Luciano, e que nela eram sacrificados gados, ovelhas e cabras (A deusa síria, 49). Era nessa ocasião que ocorria a castração de ordenação dos sacerdotes.

O jovem a quem isso está destinado lança fora as vestes, avança em alta gritaria para o meio da multidão, saca de uma faca, que, segundo me parece, está ali [para esse fim] desde há muitos anos, e, pegando nela, castra-se a si mesmo, e depois corre por toda a cidade, e leva nas mãos os órgãos que cortou. E da casa, seja qual for, para dentro da qual ele lançar os seus órgãos, dessa mesma recebe uma veste feminina e ornatos de mulher. Eis como eles procedem aquando da castração. (Luciano, A deusa síria, 51) ${ }^{35}$

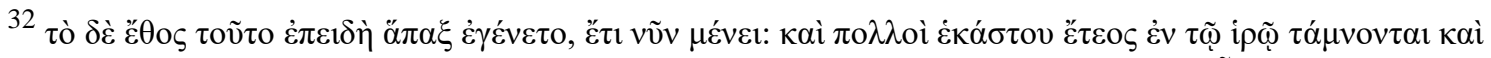

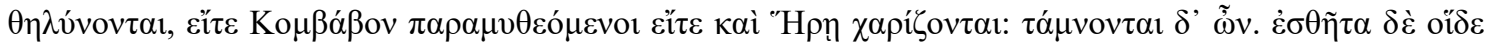

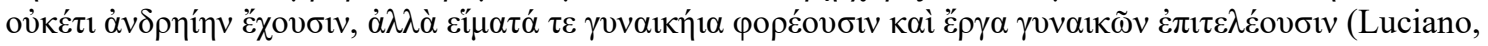
A deusa síria, 27).

${ }^{33}$ O termo que Luciano usa aqui é $\dot{\alpha} \tau \varepsilon \lambda \hat{\varepsilon} \alpha$ (ver nota 30), que não chega ao final, que não finaliza um ato, aquele que não tem propósito e, em minha interpretação, aquele que não tem utilidade, pois perdeu sua potência/virilidade.

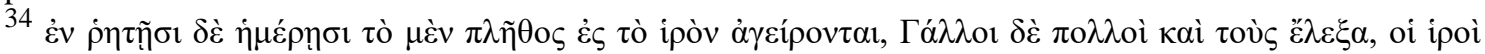

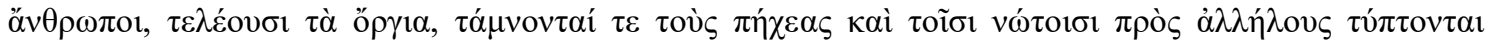
(Luciano, A deusa síria, 50).

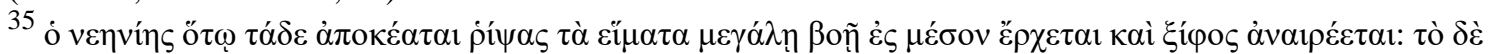

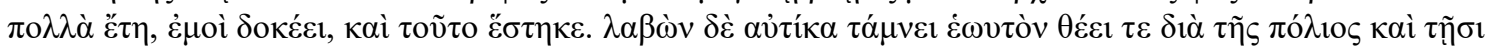


Mare Nostrum, ano 2020, v. 11, n. 1 .

Assim sendo, há a ideia do corte dos órgãos genitais masculinos no mito e no rito contados por Luciano. Chama a atenção aqui a ideia de que a festa da Deusa Síria, mostrada por Luciano, bem como a de Cibele, como comentado em nota, acontecerem no início da primavera. Isso aponta para o atributo de fertilidade e para a ligação com a vegetação das deusas, o que pode ser um elemento importante para a compreensão da natureza dos ritos de castração em tais cultos. Ainda que Luciano não diga claramente quais órgãos eram cortados, ele comenta que eles eram apresentados nas casas que recebiam os sacerdotes. Com isso, penso que ele mostra crer na retirada de partes do corpo dos iniciados de forma material e fornece elementos para compreendermos que o ato era bem visto e bem recebido por conta de uma crença em seus atributos simbólicos.

Mesmo sendo Luciano sírio da cidade de Samósata, não deixa de apresentar o ritual que acontece no templo de Atargátis com ares de exotismo. Por meio de seu relato é possível perceber como a identidade pode ser algo mais flexível e não dependente necessariamente do lugar de nascimento de uma pessoa. Além do mais, para um escritor do Império Romano como Luciano, se aproximar da cultura greco-romana das elites governantes podia ser uma forma de negociações por status e posição social. Parece ter havido uma tradição no Império Romano em se ver os sírios como femininos, o que está na Sátira III de Juvenal, por exemplo. Dessa maneira, ao descrever os ritos do templo de Atargátis com possíveis exageros e conduzindo homens à feminilidade, Luciano pode estar se afastando da Síria. Da mesma forma, pode estar mostrando aos seus leitores que, mesmo sendo sírio de nascimento, não compartilhava daquelas crenças que eram também variadas numa mesma província imperial, lembrando que o que os romanos chamavam como Síria antiga era uma região de costumes assírios, fenícios, árabes, hebreus, persas, gregos, etc., em encontros variados.

Ainda se tratando dos sírios, o imperador de origens sírias Marco Aurélio Antonino (218-222), conhecido na tradição como Heliogábalo, também se envolveu em cerimônias religiosas que parecem ter realizado castrações iniciáticas. Trata-se de seu sacerdócio a Elagabal, divindade solar da cidade de Emesa, de onde vinha Heliogábalo. Dião Cássio, senador e historiador contemporâneo de Heliogábalo, deixou sua visão sobre tal prática presente nos ritos em que o imperador era sacerdote:

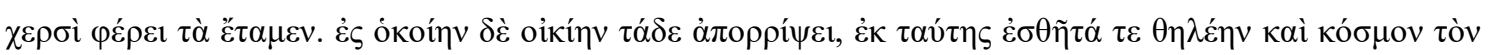

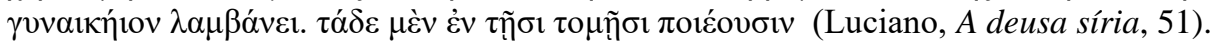


Semíramis Silva. "Por que de galo, então, chamamos quem se castra [...]?"

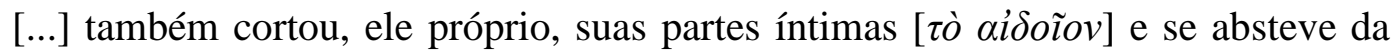
carne de porco, com o fundamento de que sua devoção deveria ser mais pura. Mas

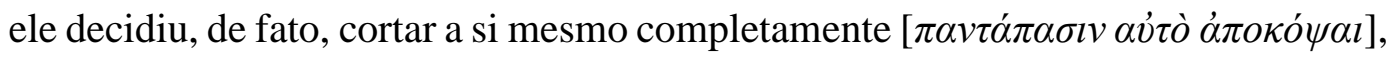
esse seu desejo foi motivado unicamente por sua moleza. Seus feitos foram parte dos requisitos sacerdotais de Elagabal, e, da mesma forma, ele mutilou muitos de seus companheiros [...]. (Dião Cássio, História Romana, LXXX, 11, 1-2. Tradução $\operatorname{minha})^{36}$

Como é possível ler, Dião Cássio tenta retirar o valor religioso da prática do imperador, considerando-a como parte de seu desejo em se tornar uma mulher, o que era bastante negativo para a imagem de Heliogábalo, a pessoa de mais alto status do Império, que o historiador buscava apresentar. No entanto, Dião acaba comentando, na sequência, que a castração era parte do sacerdócio de Elagabal, o que era realizado também em outros iniciados, segundo conta. Mas, querendo transmitir ainda mais a ideia negativa da inversão de Heliogábalo para o feminino, com a menção à sua moleza ( $\tau \tilde{\eta} \varsigma \mu \alpha \lambda \alpha \kappa i \alpha \varsigma)$, ele retira a carga religiosa e até mesmo ascética do rito. ${ }^{37}$ Para isso, Dião cita, de forma bastante hiperbólica e pejorativa, que o verdadeiro desejo de Heliogábalo era ter uma

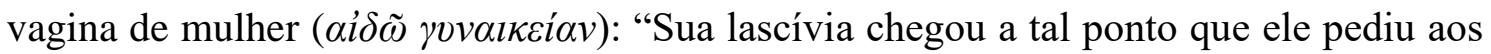
médicos que inventassem a vagina de uma mulher em seu corpo, por meio de uma incisão, prometendo a eles grandes somas como pagamento" (Dião Cássio, História Romana, LXXX, 16, 7). ${ }^{38}$

Provavelmente, a partir dessas descrições de Dião Cássio, o escritor da História Augusta, uma série de biografias imperiais da Antiguidade Tardia cuja autoria é desconhecida, ${ }^{39}$ comparou Heliogábalo aos sacerdotes de Cibele. A Vida de Heliogábalo

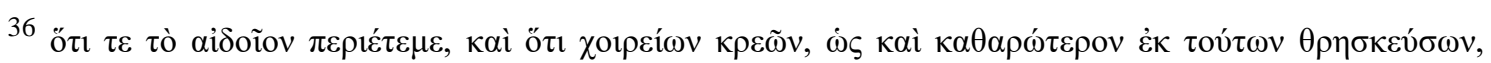

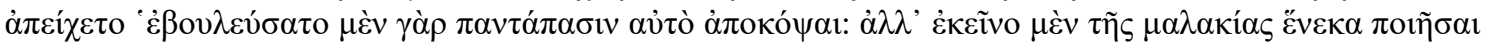

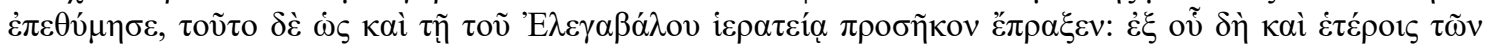

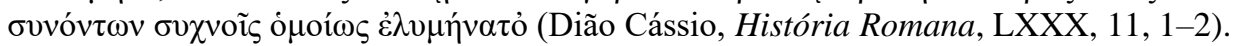

${ }^{37}$ Vejo um ascetismo apresentado por Dião na negação de Heliogábalo em comer carne de porco.

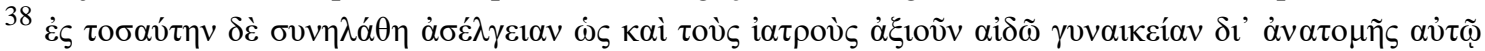

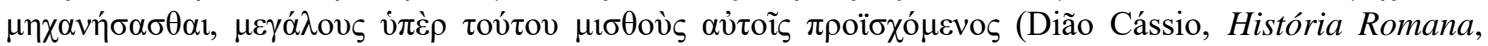
LXXX, 16, 7).

${ }^{39}$ A autoria da Vida de Heliogábalo da $H A$ tem sido atribuída pelos estudiosos a Élio Lamprídio, possível pseudônimo de um escritor cuja identidade não é conhecida. Sobre o debate em torno da autoria e data da HA, ver a Introdução de David Magie a sua tradução dessa obra publicada pela Harvard University Press.
} 
traz, de forma bastante curiosa, o falo como um elemento da vestimenta do imperador e faz uma alusão a esse órgão sexual envolvido nos ritos religiosos de Heliogábalo e dos galli: $:^{40}$

Ele balançou a cabeça entre os eunucos fanáticos, colocando órgãos genitais amarrados e fez tudo o que os galli faziam, carregava a imagem da deusa [referindose a Cibele] para fora do lugar que era seu santuário. (História Augusta, Vida de Heliogábalo, 7, 2. Tradução minha) ${ }^{41}$

Diante do que foi apresentado, é possível perceber que os autores greco-romanos do Império apresentam as práticas de castração ritual como algo totalmente indigno do uir romano, o cidadão dos grupos sociais mais abastados, aquele que deveria manter as virtudes de excelência. Os sacerdotes castrados são mostrados possuindo total falta de domínio de si, são desmedidos, descontrolados, frenéticos e luxuriosos. Os processos de castração os deixavam corrompidos, moles e sem o membro viril, o símbolo da dureza e da força masculina. Tudo isso os transformava em mulher.

Mesmo que o culto de Cibele fosse oficializado em Roma, de forma a ocupar um lugar importante no calendário festivo da cidade, assim como o culto de Atargátis e Elagabal eram aceitos, ${ }^{42}$ seus sacerdotes eram vistos como estrangeiros quando praticavam estes atos que lhes retiravam os valores viris. Ou seja, a dimensão de gênero aqui precisa ser cruzada com a dimensão da identidade cultural. O uir romano, mesmo que fosse um provincial que havia recebido a cidadania, precisava se comportar com uma série de valores do universo masculino normativo, que iam desde cuidados com o corpo até manter o papel ativo na guerra e a posição insertiva nas relações sexuais, fosse com homens ou com mulheres. A moderação (Gravitas, em latim, $\Sigma \omega \varphi \rho o \sigma v ́ v \eta$, em grego) nas relações sexuais, sociais e políticas era protocolo básico dessa virilidade. Junto com a moderação/controle vinha a dominação (imperium) de si e dos outros, como observou

\footnotetext{
40 Sobre este objeto fálico nas vestimentas sacerdotais de Heliogábalo, ver Krengel (1997) e Silva (2019).

41 iactavit autem caput inter praecisos fanaticos et genitalia sibi deuinxit et omnia fecit quae Galli facere solent, ablatumque sanctum in penetrale dei sui transtulit (História Augusta, Vida de Heliogábalo, 7, 2).

42 Sobre Elagabal, as pesquisas arqueológicas localizam um templo para divindades de origens siríacas construído na região do Transtevere em Roma. Os artefatos encontrados neste local mostram o culto de Elagabal em Roma antes do governo de Heliogábalo, provavelmente durante o reinado de Septímio Severo e Caracala (Arrizabalaga y Prado, 2014, p. 147).
} 
Craig Williams (2010, p. 139). Na falta desses valores, cidadãos das províncias podiam ser considerados como estrangeiros, mas, na sua adoção, estavam dentro da romanitas e eram aceitos sem maiores críticas nos textos dos aristocratas, muitos dos quais também eram provinciais, como Marcial, Apuleio e Luciano, por exemplo.

Um caso paradigmático sobre isso é o contraste nas imagens dos imperadores sírios Heliogábalo e seu sucessor, primo e filho adotivo, Severo Alexandre (222-235). Ambos foram sacerdotes de Elagabal, seguindo uma tradição familiar. No entanto, o que é possível ver nos textos dos historiadores Dião Cássio e Herodiano é que Heliogábalo não respeitava os valores da romanitas latina, tanto em sua forma de governar, como em uma série de elementos de seu comportamento, como vestimentas, maquiagens, uso desmedido dos prazeres, devoção exagerada a Elagabal, etc. Severo Alexandre, ao contrário, parece ter se portado mais próximo aos padrões romanos na visão dos autores (Dião Cássio, História Romana, Fragmento do Livro LXXX. Herodiano, História de Roma, VI), desde o uso tradicional da toga até a emissão de suas moedas, mais respeitosa aos deuses tradicionais do panteão romano do que seu antecessor, que realizou uma forte cunhagem em honra ao deus sírio Elagabal em relação à cunhagem para Júpiter e Marte, por exemplo (Manders, 2006). ${ }^{43}$ Sobre a questão do sacerdócio de Severo Alexandre a Elagabal envolver sua emasculação, nada é comentado nos textos, ao contrário do que é feito em relação ao desmedido Heliogábalo.

Portanto, para compreender melhor as representações dos sacerdotes castrados, é preciso lê-las dentro de uma proposta interseccional, onde são vistas sempre como prática do outro, logo, como femininas e indignas de um cidadão romano tradicional. ${ }^{44}$ Não quero

\footnotetext{
43 Seguindo as ideias de Erica Manders (2006, p. 137), não acredito que Severo Alexandre tenha sido somente tradicional aos costumes romanos como os textos apontam. É possível que muitos costumes sírios tenham sido mantidos em seu governo, como indica seu próprio sacerdócio a Elagabal. Mas, certamente, ele buscou manter uma distância considerável de Heliogábalo. A melhor fonte textual com informações sobre Severo Alexandre, contemporânea a seu governo, é a obra de Herodiano (História de Roma, VI), uma vez que Dião Cássio morreu antes de concluir a parte de sua obra voltada a esse princeps, trazendo poucas informações sobre ele. Já sobre Heliogábalo, tenho trabalhado em meus textos o quanto Heliogábalo desviava das tradições latinas em alguns pontos, mas, da mesma forma, o quanto os textos de Dião Cássio e Herodiano são carregados de exageros para difamar o imperador, com acentuados interesses políticos. Sobre a imagem bárbara de Heliogábalo nos textos, ver Silva 2017.

44 A análise interseccional é uma proposta de pesquisadoras/es ligadas/os aos Estudos culturais e póscoloniais, que analisam interseccionalidades entre aspectos de gênero, raça e classe (como os trabalhos de Brah, 2006 e Shohat, 2004). Tais estudos analisam documentos da contemporaneidade, percebendo marcadores de diferença dentro destas três categorias que, na proposta interseccional, devem ser analisadas de forma articulada e sem hierarquias. Como escrevi em outro artigo de minha autoria (Silva, 2018), no entanto, os conceitos de raça e classe devem ser repensados para a análise do Império Romano, uma vez que não cabem para o período. Desta forma, opto por usar os conceitos de gênero, identidade cultural e status social.
} 
Mare Nostrum, ano 2020, v. 11, n. 1 .

com isso afirmar que elas não fossem femininas para seus próprios iniciados. Ou seja, não quero dizer que tornar-se gallus ou sacerdote de Atargátis e Elagabal não significava uma transgenerização para o próprio sacerdote. Mas, infelizmente, não nos restam testemunhos dos próprios sujeitos para fazer esta assertiva com propriedade. Will Roscoe (1996, p. 228) defende que em sociedades patriarcais e falocêntricas, personagens como os galli devem ser considerados como uma forma de libertação, uma maneira de escapar das exigências sociais ou sexuais de papéis masculinos patriarcais. Esse estudioso percebe que tais práticas religiosas envolviam transgressão de gênero, a homossexualidade dos sacerdotes e técnicas rituais extáticas (Roscoe, 1996, p. 128). Trazendo uma ideia que parece corroborar Roscoe em alguns pontos, Piotr Scholz (2001, p. 112) diz:

[...] nós podemos inferir que a castração era uma prática muito difundida na qual, como já pudemos notar, servia a variadas propostas. Não era apenas parte das atividades cultuais; ela realizava a esperança de homossexuais que sentiam que eles podiam preservar sua juventude e viver como catamitas (pathici), prostitutos masculinos.

O historiador Renato Pinto (2011, p. 195) também escreve:

[...] seria possível pensarmos que transexuais encontrassem no culto de Cibele e de Átis um ambiente mais acolhedor e pudessem exercer, não somente suas práticas sexuais, mas, principalmente, sua identidade sexual. O erótico, os aspectos identitários e o sagrado poderiam se misturar sem problemas neste cenário.

Concordo que estes sacerdotes destoavam dos padrões de gênero da elite grecoromana governante, da qual faziam parte os escritores dos textos e ressalto que, como já escrito, gênero, identidade cultural, poder e religiosidade estavam imbricados. Mesmo não havendo como saber o que isso significava em termos de gênero para os envolvidos, as representações são o real para os escritores e é no feminino que estes personagens eram vistos. No entanto, prefiro não utilizar a ideia de identidade sexual, seguindo os passos de Michel Foucault (2009, 2010) e David Halperin (2002) que usaram o método genealógico para compreender que na Antiguidade greco-romana não havia identidades sexuais marcadas como homossexual, heterossexual, transexual e bissexual 
propriamente. Tais categorias discursivas da sexualidade são fruto de discursos científicos contemporâneos, criados a partir do século XIX. Assim sendo, compreendo que havia sujeitos que destoavam das normas e, especialmente, das éticas de gênero das elites governantes, pelo menos nas representações isso está muito claro. Porém, estes sujeitos precisam ser compreendidos nas singularidades, dispersões e descontinuidades históricas. Tais sujeitos podiam ter desejos e preferências eróticas, no entanto, essas são inalcançáveis pela natureza da documentação que chegou até os dias atuais. Além disso, suas preferências eróticas não devem ser sobrepostas às suas práticas religiosas e nem marcadas por categorias modernas. No caso da afirmação de Scholz acima citada, há ainda que se considerar que esse historiador parece generalizar tipos de castrados, misturando os sacerdotes tratados neste artigo com os jovens eunucos escravos que eram objeto de luxo entre homens da elite romana.

Voltando à análise das representações nos textos antigos, outro ponto importante a ser destacado é a questão social dos envolvidos no rito, que também está interseccionado com gênero e identidade social nas representações. Como analisei, pelo menos Juvenal (Sátira VI) apresenta implicitamente sua aversão ao rito de Cibele ligado à plebe de Roma. Tito Lívio (Histórias, XXIX, 14, 17-19) diz que o povo recebeu em massa o culto da Grande Mãe. O deus sírio Elagabal também parece ter sido bastante aceito pela plebe de Roma. Herodiano, historiador contemporâneo de Dião Cássio e do imperador Heliogábalo, fornece uma pista sobre isso ao contar que o povo corria junto à quadriga que levava o símbolo do deus até seu templo fora de Roma. De forma exagerada, Herodiano ainda diz que uma multidão era pisoteada em meio às celebrações da festa de Elagabal promovida por Heliogábalo (História do Império Romano, V, 6, 8-10).

Jaime Alvar (2008) traz uma importante reflexão sobre a questão da plebe e dos ritos de Cibele. As versões dos textos literários dizem que o culto foi introduzido em Roma porque os Livros Sibilinos e o Oráculo de Delfos teriam recomendado o culto de Cibele aos romanos a fim de que pudessem vencer Aníbal e os cartagineses. No entanto, Alvar (2008, pp. 243-244) acredita que essa versão tinha como intuito apresentar a aprovação de um culto já conhecido em Roma sob a legitimidade do Senado. A elite dirigente da cidade, segundo este historiador, sabia muito bem o que ele envolvia e tenta com isso domesticá-lo e abafar as inquietações populares expressas em um idioma 
Mare Nostrum, ano 2020, v. 11, n. 1 .

religioso. ${ }^{45}$ No entanto, ainda assim, o conflito com o culto foi contínuo, o que ecoa nas representações dos textos de tom aristocrático citados neste artigo.

No mais, a prática da castração ritual e a função dos galli com suas vestimentas e adereços tidos como femininos, parece ter sido parte fundamental dos ritos de Cibele e, por isso, chega a ser proibida de ser realizada por cidadãos romanos, como conta Dionísio de Halicarnasso em passagem analisada. Indigno de ser praticado por um cidadão romano, o rito dos sacerdotes castrados ganha tons retóricos altamente potencializados na literatura.

É também como exagero retórico que Alvar (2008, pp. 247-248), com quem concordo, lê as informações da literatura sobre o corte do pênis dos sacerdotes castrados. Para ele, é totalmente improvável que os galli removessem os testículos, o escroto e o pênis, como defendeu Philippe Borgeaud (1996, apud Alvar, 2008, p. 247). Além dessa prática ser incomum nos exemplos históricos que temos de outras sociedades, a perda de sangue seria fatal e, para Alvar, mesmo em estado frenético, seria difícil que indivíduos se voluntariassem a isso. Sobre a remoção do pênis, Alvar também acredita não ser uma realidade do rito, pois

[...] a perda do pênis significa que a uretra deve ser mantida aberta por meio de um tubo para impedir que oclua; e isso, é claro, teria levado, sob condições sanitárias antigas, a infecções urinárias constantes. Se fosse esse o caso do mundo grecoromano, certamente teríamos ouvido falar sobre isso nos escritos médicos. (Alvar, 2008, p. 248)

Partindo dessas ideias, Alvar (2008, p. 250) defende que eram os testículos e o escroto as partes removidas nos galli. Nesse sentido, a leitura de Alvar, que me parece bastante acertada, é que os escritores do Império não tinham interesses técnicos, não estavam preocupados com o que era removido em si nos rituais de castração dos sacerdotes. Eles estavam tratando do "significado social da masculinidade", ressalta Alvar (2008, p. 250). Marcial, por exemplo, jogava com uma série de convenções de

\footnotetext{
45 A partir de escavações arqueológicas no Palatino, que descobriram terracotas votivas de Átis criança no período anterior à oficialização dos ritos, Alvar (2008, pp. 245-246) conjectura que o culto já conhecido em Roma deveria ser bem diferente do exotismo descrito nos textos. Naquela ocasião, provavelmente, Cibele era considerada como uma deusa mãe protetora da saúde da família e das crianças. O culto era popular e não há evidências arqueológicas sobre o excesso desenfreado apontado na literatura.
} 
oposições, inversões e equivalências: masculino e feminino, não muito masculino = quase feminino, vulva e ânus, boca e ânus, língua = pênis, cabeça = pênis (Alvar, 2008, p. 249). Portanto, é preciso ler os textos com cuidado, percebendo os interesses dos escritores e os elementos próprios da arte de suas escritas.

Além do mais, é interessante notar que os autores greco-romanos não comentam o significado religioso em si das práticas dos galli e dos sacerdotes de Atárgatis. Eles apenas relatam suas origens mitológicas e comentam alguns detalhes do ritual em suas visões exoticizadas e exageradas, mostrando seu espanto em tom ora de terror, ora de escárnio. De maneira semelhante, os ritos de Heliogábalo somente recebem críticas por parte de Dião Cássio, sem nenhuma explicação sobre a função e o simbolismo religioso das intervenções no corpo que são vistas como retirando a virilidade do iniciado.

Diante disso, concordo com Benedito Ribeiro Junior (2016, p. 139) que, ao analisar os galli nos poemas de Marcial defende que: “O enfrentamento de Marcial aos galli revela muito mais do próprio Marcial do que dos eunucos, expondo as tentativas romanas discursivas de criação e manutenção de identidades (religiosa, de gênero, romana) [...]." Estendo a observação de Ribeiro Junior sobre os galli de Marcial para os sacerdotes castrados de maneira geral na literatura greco-romana. Embora, como já ressaltei, prefiro optar por não fazer uma leitura marcada pela ideia de identidades de gênero na Antiguidade baseadas em modelos e classificações modernas.

Para tentar se aproximar das possíveis naturezas simbólico-religiosas destes ritos é preciso recorrer a um estudo sobre as práticas, indo além das representações literárias dentro das possibilidades existentes diante de uma documentação escassa. Tal empreitada requer um grande esforço interpretativo, além de um cruzamento crítico de análises da cultura material com as informações trazidas no material literário. Pelos objetivos deste artigo não entrarei neste questionamento. Para isso ser possível, acredito também ser necessário um estudo mais recortado do ritual e dos personagens, como faz Alvar em suas pesquisas sobre Cibele e os galli e como tenho buscado fazer em minhas pesquisas sobre Heliogábalo e Elagabal. 
Mare Nostrum, ano 2020, v. 11, n. 1 .

\section{Considerações finais}

Para finalizar este artigo, devo frisar que os personagens aqui trabalhados se tornam muito interessantes para se pensar uma série de questões de gênero em meio às identidades culturais, alteridades e demarcações de espaços sociais e políticos no contexto romano. Tornam-se, também, inquietantes de serem analisados em nossa contemporaneidade, diante da explosão de identidades de gênero, da formação de movimentos cujas siglas não param de incorporar novas categorias e, inclusive, da própria implosão de modelos identitários, como a proposta central da teoria queer, por exemplo. Talvez essa seja a reflexão mais interessante que o estudo destes personagens possa trazer para os dias de hoje.

Em relação à Antiguidade, gostaria de comentar que, mesmo que estes ritos de fato possam ter como fundo, ou como um dos fundos, a questão da fertilidade, eles não devem ser encerrados apenas a partir desse elemento, isso seria uma forma de esconder as possíveis transgressões às normativas de gênero do mundo antigo e apagar o valor que tais exemplos podem ter para estudos das dissidências e, da mesma maneira, das normativas e éticas antigas. As questões de gênero, identidade cultural, controle social e poder que os estudos das práticas e representações destes sacerdotes trazem têm um enorme potencial para a compreensão de diferentes facetas das sociedades antigas e, até mesmo, da construção de sua historiografia. Pensar como historiadores e historiadoras têm, em diferentes momentos históricos, com diferentes perspectivas, métodos e até opções políticas, analisado os sacerdotes castrados, é outro caminho possível.

Nesse caminho, o orientalismo vem à tona. Mostrei como, nos textos dos autores antigos, os sacerdotes castrados foram representados como o outro feminino, vindo das regiões orientais. A historiografia contemporânea, fortemente marcada pelo Colonialismo e pelo Orientalismo, não deixa de repetir, em grande medida, o peso do exotismo oriental destes sacerdotes. Personagens que, no entanto, caminhavam pelas cidades do Império Romano e traziam gregos e romanos para um ritual potencialmente exotizado pelos escritores dos testemunhos textuais. Um personagem considerado castrado chegou até a se tornar imperador de Roma, como foi o caso de Heliogábalo, apresentando como tais ritos estavam bem presentes na capital do Império e mesmo entre membros das elites detentoras dos mais altos cargos. 
Semíramis Silva. "Por que de galo, então, chamamos quem se castra [...]?"

Portanto, os sacerdotes castrados podem ser paradigmáticos ao mostrar como nossa historiografia olha para a Antiguidade com olhares imperialistas modernos, que urge ser descolonizada e realizar uma crítica mais densa dos textos. Não basta dizer que estes textos são produtos de juízos de valores de aristocratas antigos. É preciso perceber como eles ainda moldam nossos imaginários e são usados, mesmo que inconscientemente, para trazer estereótipos ressignificados pelas marcas do colonialismo contemporâneo.

Recebido em 20.02.2020, aprovado em 23.03.2020. 
Mare Nostrum, ano 2020, v. 11, n. 1 .

\section{REFERÊNCIAS BIBLIOGRÁFICAS}

Fontes:

Aelius Lampridius. (1993). Antoninus Elagabalus. In: Scriptores Historiae Augustae. (Vol. II). (Magie, David trad.). Harvard University Press, 104-176 (The Loeb Classical Library).

Apuleio. (2019). O asno de ouro. (Guimarães, Ruth. Trad., prefácio e notas). Editora 34.

Babrio, Fábulas de Babrio (1985). In: Fábulas de Esopo, Vida de Esopo, Fábulas de Babrio. (Gual, Carlos García; introd. geral). La Peña, P. Bádenas; J. López, Facal. Introds., trad., notas). Editorial Gredos, (Biblioteca Clásica Gredos).

Catulo. (1996). O Livro de Catulo. (J. A. Oliva Neto trad., introd., notas). Edusp.

Cassius Dio. (1955). Dio's Roman History. (Cony, Earnest. Trad.). William Heinemann/Harvard University Press. (The Loeb Classical Library).

Cicero. (1966). De Haruspicum responso oratio. Tome XIII, 2. (Wuilleumier, Pierre; Tupet, Anne-Marie. Ed. e trad.). Les Belles Lettres.

Dionysius of Halicarnassus. (1937). Roman Antiquities. Vol. I, Books (1-2). Cary, Earnest (trad.). Harvard University Press. (The Loeb Classical Library).

Firmicus Maternus. (1970). The Error of the Pagan Religions. A. Forbes., Clarence (trad.). Newman Press.

Herodian. 1970. History of the Empire from the time of Marcus Aurelius. Vol. II. Books (V-VIII). Whittaker, C. R. (trad.) William Heinemann/Harvard University Press. (The Loeb Classical Library).

Juvenal. Satire VI. (1998). In The Sixteen Satires. (P. Green, trad.). Penguin Classics, $127-175$.

Juvenal. Sátira VI. In Sátiras. (F. A. M. Bastos, trad.). Ediouro, [s/d], 48-66.

Lucian. Lucius or the ass. (2001) In Vol. VIII. (M. D., Macleod, trad.) Harvard University Press, 47-145 (The Loeb Classical Library). 
Semíramis Silva. "Por que de galo, então, chamamos quem se castra [...]?"

Lucian. The syrian goddess. (2003). (J. L. Lightfoot, introd., trad., comentários). Oxford University Press.

Luciano. Lucio o El asno. (1988) In Obras II. (J. L. N. González, trad., notas). Editorial Gredos, 320-363 (Biblioteca Clásica Gredos).

Luciano. A deusa síria. (2013). In Luciano [VII]. (C. Magueijo, trad. grego, introd. e notas). Imprensa da Universidade de Coimbra, 177-207.

Lucrécio. (2015). Da natureza das coisas. (L. M. G. Cerqueira. Trad., introdução e notas). Relógio d'Água,

Ovídio. Fastos. (2015). (M. M. Gouvêa Júnior, trad.). Autêntica Editora.

Santo Agostinho. (1996). Capítulo XXVI. A torpeza dos mistérios da Grande-Mãe (Livro V). In A cidade de Deus. (Vol. I). (J. D. Pereira, trad., prefácio, nota biográfica, transc.). Edição da Fundação Calouste Gulbenkian, 671-673.

Tito Lívio. (1993). Historia de Roma desde su fundación. (Libros XXVI-XXX). (J. A. V. Vidal, traduc. e notas). Editorial Gredos, (Biblioteca Clásica Gredos).

\section{Estudos:}

Alvar, J. (2008). Romanising oriental Gods: myth, salvation, and ethics in the cults of Cybele, Isis, and Mithras. Brill.

Arrizabalaga y Prado, L. (2014). The Emperor Elagabalus. Fact or Fiction? Cambridge University Press.

Beltrão, C. (2012). Magna Mater, Claudia Quinta, Claudia Metelli (Clodia): A construção de um mito no principado augustano In Cândido, M. R. (Org.). História das Mulheres na Antiguidade. NEA/UERJ, 63-93.

Brah, A. (2006). Diferença, diversidade, diferenciação. Cadernos Pagu, 26, 329-376.

Brandão, J. S. (2014). Reia. In Dicionário mítico-etimológico. Vozes, 555.

Butler, J. (2010). Problemas de gênero. Feminismo e subversão de identidade. Civilização Brasileira. 
Mare Nostrum, ano 2020, v. 11, n. 1 .

Cairolli, F. P. (2014). Marcial brasileiro. [Tese de doutorado, USP]

Chartier, R. (1988). A História Cultural. Entre práticas e representações. Rio de Janeiro: Bertrand Brasil,

Chartier, R. (1991). O mundo como representação, Estudos Avançados, 11 (5), 173-191.

Foucault, M. (2009). O cuidado de si. História da sexualidade. (Vol 3). Graal.

Foucault, M. (2010). O uso dos prazeres. História da sexualidade. (Vol. 2). Graal

Gonçalves, R. T., Gontijo Flores, G., Stocco, A. L., Cozer, A., Grochocki, M. \& Lautenschlager, R. (2015). Galiambos brasileiros: tradução e performance de Catulo 63. Translatio, 10, 70-78.

Halperin, David. (2002). How to do the History of Male Homosexuality. In How to do the History of Homosexuality. The University of Chicago Press, 104-137.

Krengel, E. (1997) Das sogenannte, Horn” des Elagabal - Die Spitze eines Stierpenis. Eine Umdeutung als Ergebnis fachübergreifender Forschung, Jahrbuch für Numismatik und Geldgeschichte, 47, S., 53-72.

Manders, E. (2006). Religion and Coinage. Heliogabalus and Alexander Severus: two extremes? In Stronk, J. P. \& Weerd, M. D. (Edits.). Talanta. Proceeding of the Dutch Archaeological and Historical Society, (vol. XXXVI-XXXVIII), 123-138.

Pinto, R. (2011). Duas rainhas, um Príncipe e um Eunuco: masculino e feminino nos estudos sobre a Bretanha Romana. [Tese de Doutorado, UNICAMP]

Ribeiro Junior, B. I. (2016). Para além da heteronormatividade: uma análise dos eunucos representados por Estácio, Marcial e Suetônio (Roma, 80-121 d.C.). [Dissertação de Mestrado, UNESP/Assis]

Roscoe, W. (1996). Priests of the Goddess: Gender Transgression in Ancient Religion. History of Religions, (vol. 35), n. 3, 195-230.

Scholz, P. O. (2001). Eunuchs and Castrati. A Cultural History. Markus Wierner Publishers, 
Semíramis Silva. "Por que de galo, então, chamamos quem se castra [...]?"

Shohat, E. (2004). Des-orientar Cleópatra: um tropo moderno da identidade. Cadernos Pagu, 23, 11-54.

Silva, S. C. (2017). Barbaridade versus Humanitas no Principado Romano: a política e a construção da imagem do imperador Heliogábalo (século III EC). Alétheia Estudos sobre Antiguidade e Medievo, (v. 2), 114-136.

Silva, S. C. (2018). Identidade cultural e gênero no Principado Romano: uma proposta de análise interseccional das representações do imperador Heliogábalo (século III E.C.). Phoînix, 24, 142-166.

Silva, S. C. (2019). Heliogábalo vestido divinamente: a indumentária religiosa do imperador sacerdote de Elagabal. Arys. Antigüedad: Religiones y Sociedades, vol. $1,251-276$.

Thuillier, J-P. (2013). Virilidades romanas: vir, virilitas, virtus. In Corbin, A. (et al.). História da virilidade. (Volume I). Vozes, 71-124.

Williams, C. (2010). Roman Homosexuality. Ideologies of Masculinity in Classical Antiquity. Oxford University Press. 


\title{
"Why, Then, We Call Gallus The One Who Is Castrated [...]?" Intersectionality In Representations Of Castrated Priests In THE ROMAN EMPIRE
}

\author{
Semíramis Corsi Silva
}

\section{ABSTRACT}

This article aims to analyze textual representations of the priests who have been considered practitioners of rituals that involved cutting off their genitals. Such interventions, treated here as castrations, were considered as a loss of virility and a practice of transgenderization from masculine to feminine in the Greco-Roman literature of the imperial period. Castrated priests can be seen in the myth of Attis (the consort of the Phrygian goddess Cibele, Magna Mater), in the literature on the priests of this goddess (the galli) and in the textual representations of the priests of the Syrian goddess Atargatis and of the Emperor Elagabalus (218-222). Reports of these practices left by their practitioners are non extant. Thus, much of the documentation we have about castrated priests refers to representations made by their critics. Therefore, the sources used for this study are composed of Greeco-Roman literary texts. In this article, such texts will be analyzed through an intersectional perspective, considering the description of the priests from the construction of the other non-Greco-Roman and under the gender norms for the uir, the citizen of the Roman Empire' high social groups.

\section{KEYWORDS}

Castrated priests; galli; Elagabalus; representations; intersectionality. 